Check for updates

Cite this: Chem. Commun., 2017, 53, 11177

Received 8th September 2017, Accepted 18th September 2017

DOI: $10.1039 / \mathrm{c7cc07050k}$

rsc.li/chemcomm

\section{Real time detection of ESKAPE pathogens by a nitroreductase-triggered fluorescence turn-on probe $\uparrow$}

\author{
Shengnan Xu, ${ }^{a}$ Qinghua Wang, ${ }^{\mathrm{ab}}$ Qingyang Zhang, ${ }^{\mathrm{ab}}$ Leilei Zhang, ${ }^{\mathrm{b}}$ Limin Zuo, $^{\mathrm{c}}$ \\ Jian-Dong Jiang ${ }^{a c}$ and Hai-Yu Hu (D) *ab
}

The identification of bacterial pathogens is the critical first step in conquering infection diseases. A novel turn-on fluorescent probe for the selective sensing of nitroreductase (NTR) activity and its initial applications in rapid, real-time detection and identification of ESKAPE pathogens have been reported.

Bacterial infections represent the leading cause of morbidity and mortality worldwide; especially, the ESKAPE pathogens (Enterococcus faecium, Staphylococcus aureus, Klebsiella pneumoniae, Acinetobacter baumannii, Pseudomonas aeruginosa, and Enterobacter species) cause the majority of hospital infections and effectively "escape" the effects of antibacterial drugs. ${ }^{1}$ In addition to novel treatment options, there is a strong need to better diagnose bacterial infections via non-invasive molecular imaging methods. ${ }^{2}$ To this end, various methods have been developed for the detection and identification of pathogens by nuclear imaging and optical imaging. ${ }^{3}$ Among these methods, fluorescence imaging has attracted much attention due to its high selectivity, good spatial resolution, and non-invasive mode of action. ${ }^{4}$ A number of bacteria targeting fluorescent probes have been developed in the past and several are on the way to the clinic. ${ }^{5}$ A common problem with these probes is the background fluorescent signal, which requires extensive and time-consuming washing steps to remove free fluorophores. Therefore, we hypothesized that bacteria specific enzyme-triggered fluorescence turn-on probes would provide a superior diagnostic capability for bacterial infections. ${ }^{6}$ These probes exhibit only low background fluorescence in a

\footnotetext{
${ }^{a}$ State Key Laboratory of Bioactive Substances and Function of Natural Medicine, Institute of Materia Medica, Peking Union Medical College and Chinese Academy of Medical Sciences, Beijing, 100050, China.E-mail: haiyu.hu@imm.ac.cn

${ }^{b}$ Beijing Key Laboratory of Active Substances Discovery and Drugability Evaluation, Institute of Materia Medica, Peking Union Medical College and Chinese Academy of Medical Sciences, Beijing, 100050, China

${ }^{c}$ Institute of Medicinal Biotechnology, Chinese Academy of Medical Sciences \& Peking Union Medical College, Beijing, China

$\dagger$ Electronic supplementary information (ESI) available: Synthetic procedures and spectra data for all new compounds, and statistical analysis of NTR sequences, UV-VIS, FI spectral studies and confocal imaging studies. See DOI: 10.1039/c7cc07050k
}

free state and, as a result, enable real time imaging of enzyme activities with a high signal-to-noise ratio in live bacterial cells. Furthermore, these probes also would be used for bacterial species identification via the differences of fluorescence turn-on response of each pathogen to the probe.

Nitroreductases (NTRs), a family of flavin-containing enzymes, are able to metabolize nitrosubstituted compounds using the reducing power of nicotinamide adenine dinucleotide $(\mathrm{NAD}(\mathrm{P}) \mathrm{H})^{7}$ These enzymes are present in a wide range of bacterial genera and, to a lesser extent, in eukaryotes except hypoxic tumour cells and tissues, which make them a potential bacterial imaging target. Multiple sequence alignments of NTR proteins from E. coli and ESKAPE pathogens showed low similarity between each sequence pair (Fig. S1a, ESI $\dagger$ ). Moreover, the phylogenetic tree constructed from amino acid sequences of NTR proteins also indicates that the NTRs of these seven species are not closely related (Fig. S1b, ESI $\dagger$ ). Based on statistical analysis of sequences, we envisioned that it would be possible to diagnose ESKAPE pathogens by evaluating NTR activity detection.

The detection of NTR activities within hypoxic tumour cells and tissues using fluorogenic methods has been well described recently. ${ }^{8}$ In comparison, only a few optical probes have been developed for detecting NTR activities in $E$. coli and/or bacterial lysates, ${ }^{9}$ and there appears to have been no real time NTR enzymatic activity detected and evaluated in bacterial pathogens using a fluorogenic method. In an effort to detect NTRs which could be used for real time rapid detection and identification of ESKAPE pathogens, herein we designed a bacterial cell permeable fluorogenic probe which could selectively and rapidly be triggered by NTRs. Furthermore, the probe was successfully applied for imaging of NTRs in living bacterial cells and visualized the difference of NTR levels in ESKAPE pathogens by fluorescence confocal microscopy for the first time.

In our preliminary studies, we found that the lipophilic, nearinfrared fluorescent cyanine dye Cy 5.5 with one positive charge could penetrate both Gram positive and Gram negative bacterial cell membranes and label ESKAPE pathogens (Fig. S2, ESI $\dagger$ ); therefore, Cy 5.5 was chosen as a fluorochrome. The fluorogenic 


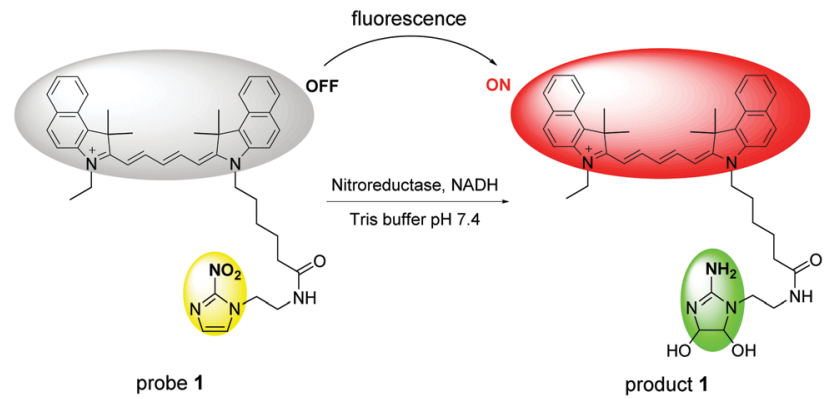

Scheme 1 The structure of probe 1 and its reaction with NTR

probe $\mathbf{1}$ was synthesized by the conjugation of a nitro-imidazole group (quencher) to Cy 5.5 and its structure was characterized by ${ }^{1} \mathrm{H}$ NMR, ${ }^{13} \mathrm{C}$ NMR and HRMS (see the ESI $\dagger$ for details). We expected the reduction of the nitro group into the amino group by NTR would result in an off-on fluorescence response (Scheme 1).

We first investigated the function response of probe $\mathbf{1}$ to purified $E$. coli NTR in vitro using fluorescence emission spectroscopy. Probe 1 was incubated in $0.05 \mathrm{M}$ Tris buffer solution at $\mathrm{pH} 7.4$, containing $500 \mu \mathrm{M} \mathrm{NADH}$. As depicted in Fig. S3b (ESI $\dagger$ ), the latent fluorescent probe 1 itself shows a very weak emission at $699 \mathrm{~nm}$ and the addition of NTR leads to an obvious fluorescence enhancement. The reduction product 1 was determined by high resolution mass spectrometry and confirmed by comparing with the chemically synthesized product 1 with HPLC (Fig. S4 and S15, ESI $\dagger$ ) and the deduced process is proposed in Scheme S4 (ESI $\dagger) .{ }^{8 a}$ Furthermore, effects of $\mathrm{pH}$ and temperature on the reaction between probe $\mathbf{1}$ and NTR were studied (Fig. S5 and S6, ESI†), which reveals that the probe functions best under physiological conditions (about $\mathrm{pH} 7.4$ and $37^{\circ} \mathrm{C}$ ). Under the optimized conditions, the fluorescence response of probe 1 to NTR at varied concentrations is shown in Fig. 1. A gradual increase in fluorescence intensity (FL intensity) was observed with the increase in the NTR concentrations, and a good linearity was obtained in the concentration range of $0.05-0.5 \mu \mathrm{g} \mathrm{mL}{ }^{-1}$, with a linear equation of $F=3.21 \times 10^{5} \mathrm{C}$ $(\mu \mathrm{g}$ per $\mathrm{mL})+3.12 \times 10^{4}(R=0.9944)$. The detection limit ( $3 \sigma / k$, in which $\sigma$ is the standard deviation of blank measurements, $n=11$, and $k$ is the slope of the linear equation) is determined to be $8.4 \mathrm{ng} \mathrm{mL} \mathrm{m}^{-1} \mathrm{NTR}$.

The apparent kinetic parameters of probe $\mathbf{1}$ catalysis by NTR were additionally determined. The rate of product 1 released from probe 1 triggered by NTR in the presence of NADH $(500 \mu \mathrm{M})$ as an electron donor was measured by adding a known concentration of probe $\mathbf{1}(7.5-25 \mu \mathrm{M})$ to the reaction mixture. As shown in Fig. S7 $(\mathrm{ESI}+)$, fluorescence intensities increase with the level-up of the concentrations of probe $\mathbf{1}$ and nearly reach a plateau in about $30 \mathrm{~min}$, which indicates that higher concentrations of probe $\mathbf{1}$ result in stronger fluorescence intensity. In contrast, the fluorescence of probe 1 without NTR (control) hardly alters during the same period of reaction time, also implying that the probe is stable in the detection system (Fig. S3b, ESI $\dagger$ ).

Next, we investigated the kinetic parameters for the enzymeactivated reaction of probe 1 . The Lineweaver-Burk plot of $1 / V$
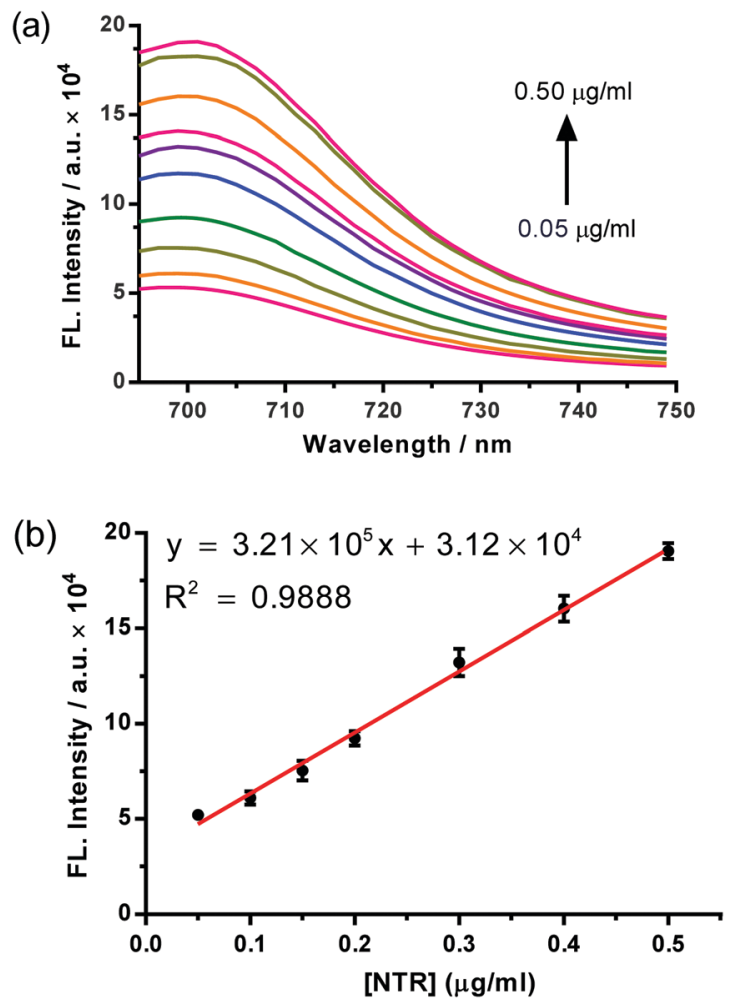

Fig. 1 (a) Fluorescence spectra of probe $1(15 \mu \mathrm{M})$ reacting with NTR at varied concentrations $(0.05,0.10,0.15,0.20,0.25,0.30,0.35,0.40,0.45$ and $0.50 \mu \mathrm{g} \mathrm{mL}^{-1}$ ) in the presence of $500 \mu \mathrm{M} \mathrm{NADH}$ at $37^{\circ} \mathrm{C}$ for $30 \mathrm{~min}$. (b) Linear correlation between the concentration of NTR and the fluorescence intensity of the reaction mixture $\left(\lambda_{\mathrm{ex}} / \lambda_{\mathrm{em}}=658 / 699 \mathrm{~nm}\right)$, data shown as mean \pm s.d. $(n=3)$.

( $V$ represents the initial reaction rate) versus the reciprocal of the probe concentration was established (Fig. S8, ESI $\dagger$ ). By fitting the data with the Michaelis-Menten equation, the corresponding Michaelis constant $\left(K_{\mathrm{m}}\right)$ and the maximum of the initial reaction rate $\left(V_{\max }\right)$ for the enzyme-activated reaction were determined to be $7.21 \mu \mathrm{M}$ and $0.020 \mu \mathrm{M} \mathrm{s}^{-1}$, respectively, which were comparable to the values reported previously. ${ }^{10}$

The specificity of probe $\mathbf{1}$ is extremely important when it is utilized for imaging NTR activity in bacteria. In order to explore the specificity of probe 1 to NTR, two sets of experiments based on interference factors and the NTR inhibitor were carried out. First, considering the complexity of the bacterial intracellular environment, the interferences of various bioanalytes were studied, including reductive biothiols (Cys, DTT, GSH and homocysteine), arginine (Arg), ascorbic acid (Vc), glucose, reactive oxygen species $\left(\mathrm{ClO}^{-}, \mathrm{H}_{2} \mathrm{O}_{2}\right)$ and inorganic salts $\left(\mathrm{CaCl}_{2}\right.$, $\mathrm{MgCl}_{2}, \mathrm{KCl}$ and $\mathrm{NaCl}$ ). Fluorescence responses of probe $\mathbf{1}$ to the tested species showed that the fluorogenic probe $\mathbf{1}$ only could be triggered by NTR but not the other interference factors, including reductive biothiols at a high concentration (Fig. 2). These experiments provide evidence that probe $\mathbf{1}$ is highly specific to NTR and hence can be used for NTR detection.

Next, we investigated the effect of a common inhibitor of NTR, dicoumarin, ${ }^{11}$ on the activity of the enzyme. When probe 1 was pre-treated with $2.5 \mu \mathrm{M}$ dicoumarin and then mixed with 


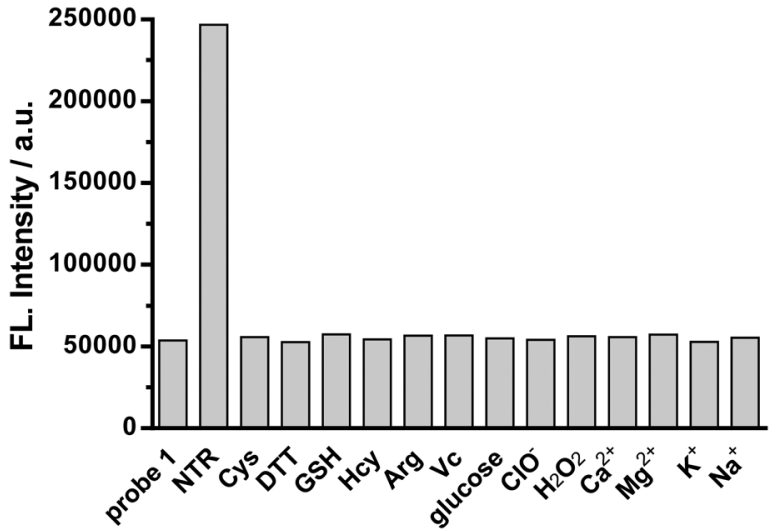

Fig. 2 Fluorescence responses of probe $1(15 \mu \mathrm{M})$ to various species: NTR $\left(1 \mu \mathrm{gL}^{-1}\right)$, Cys (1 mM), DTT (1 mM), GSH (1 mM), Hcy (1 mM), Arg (1 mM), Vc (1 mM), glucose (10 mM), ClO ${ }^{-}(10 \mu \mathrm{M}), \mathrm{H}_{2} \mathrm{O}_{2}(10 \mu \mathrm{M}), \mathrm{CaCl}_{2}(2.5 \mathrm{mM})$, $\mathrm{MgCl}_{2}(2.5 \mathrm{mM}), \mathrm{KCl}(10 \mathrm{mM})$ and $\mathrm{NaCl}(10 \mathrm{mM})$. All spectra were acquired in $0.05 \mathrm{M}$ Tris buffer $\left(\mathrm{pH}\right.$ 7.4) with $1.5 \%$ DMSO as co-solvent at $37{ }^{\circ} \mathrm{C}$ $\left(\lambda_{\mathrm{ex}} / \lambda_{\mathrm{em}}=658 / 699 \mathrm{~nm}\right)$.

NTR, the fluorescence intensity was much lower than that without dicoumarin (Fig. S9, ESI $\dagger$ ). Moreover, increasing the concentration of dicoumarin led to a progressive decrease in the fluorescence intensity of a mixture of probe 1 and NTR, confirming that the NTR activity was effectively inhibited by dicoumarin. These results confirmed that the enhanced fluorescence response of probe 1 to NTR arises from the enzyme-catalyzed reduction reaction.

Following the demonstration of the specificity of probe 1 to NTR, we examined whether probe 1 could be used to detect NTR activity in bacterial lysates. Grown E. coli cultures were treated with $5 \mu \mathrm{M}$ of probe $\mathbf{1}$ at three different initial concentrations and subjected to subsequent lysis. As shown in Fig. 3, a gradual increase in fluorescence intensity is observed with the increase in the bacterial concentration. Moreover, the addition of dicoumarin $(0.1 \mathrm{mM})$ to the bacterial culture before treatment with the probe significantly reduced the fluorescence intensity of the live E. coli, further demonstrating the specificity of the probe towards NTR.

Encouraged by the in vitro imaging data, the ability of the NTR probe $\mathbf{1}$ for real time detection and identification of

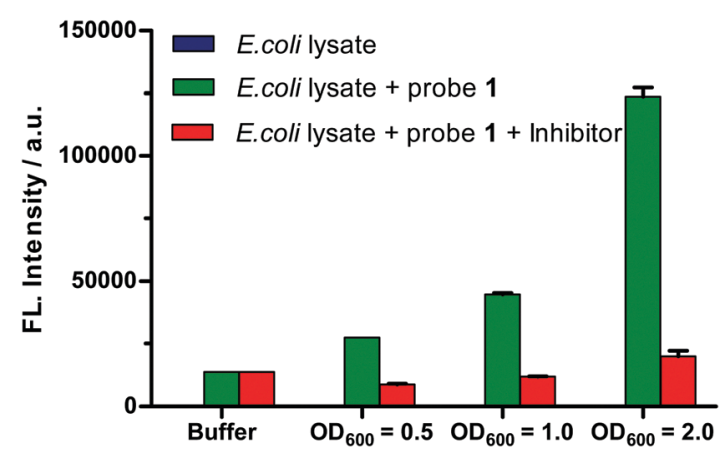

Fig. 3 Fluorescence intensity of the clarified cell lysate of $E$. coli before (blue bars) and after incubating with probe 1 ( \pm NTR inhibitor, red/green bars) at various initial bacterial concentrations $\left(\lambda_{\mathrm{ex}} / \lambda_{\mathrm{em}}=658 / 719 \mathrm{~nm}\right)$, bars represent mean values \pm s.d. $(n=3)$. medically important bacterial pathogens of the ESKAPE panel, comprising the Gram negative species $K$. pneumoniae, A. baumannii, P. aeruginosa, E. cloacae and E. coli, and as well as the Gram positive species $E$. faecium and $S$. aureus, was probed. $5 \mu \mathrm{M}$ probe 1 was incubated with seven bacterial strains in $0.05 \mathrm{M}$ Tris buffer (pH 7.4) at $37{ }^{\circ} \mathrm{C}$ for $1 \mathrm{~h}$, respectively, and the activation of probe 1 was analysed by confocal microscopy. As shown in Fig. 4(a-d) and Fig. S10 (ESI $\dagger$ ), probe 1 was readily taken up and activated by all the seven tested bacterial cells. The intensity of the nearinfrared fluorescence signal from Cy 5.5 indicated the relevant amount of probe 1 activated by NTRs in live bacteria. The quantification of Cy 5.5 fluorescence intensities in the cells revealed varying staining efficiencies among the ESKAPE pathogens (Fig. 4e). The strongest fluorescence signals from S. aureus incubated with probe 1 showed a 2.5 -fold mean increase over the weakest one from E. faecium incubation. Meanwhile, pretreatment of bacterial cells with the NTR inhibitor dicoumarin had a significant effect on probe 1 reduction, suggesting that the probe $\mathbf{1}$ was largely activated by NTR intracellularly after internalization. We believe the different fluorescence turn-on
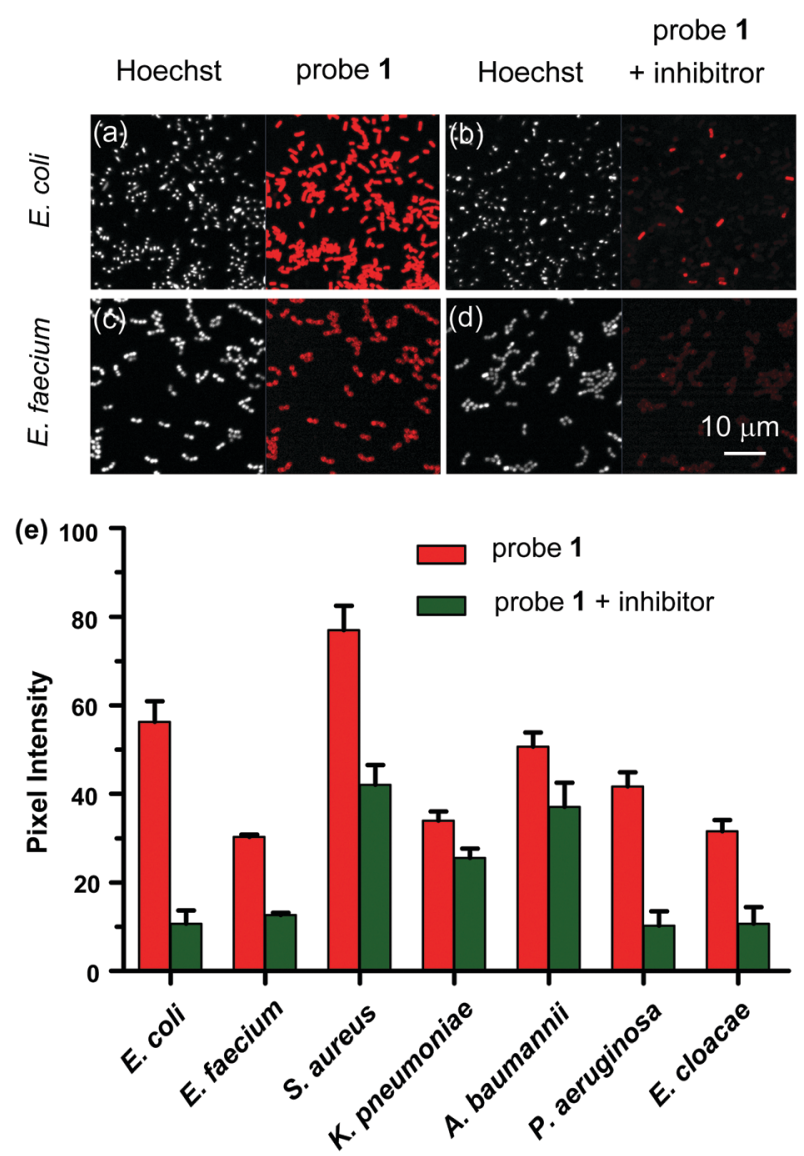

Fig. 4 Confocal microscopy images of E. coli (a and b) and E. faecium (c and d) incubated with probe 1 in the absence (a and c) or presence ( $b$ and $d$ ) of NTR inhibitor, respectively. DNA was stained with Hoechst 33258 (white), red: probe Cy 5.5 signals. (e) Quantification of fluorescence intensity of probe 1 incubated with E. coli and ESKAPE pathogens in the absence (red bars) or presence (green bars) of NTR inhibitor, respectively. Bars represent mean values \pm s.d. $(n=3)$. 
responses of probe 1 to ESKAPE pathogens are most likely due to the different amounts and/or types of NTRs in respective strains, which might make real time detection and identification of ESKAPE pathogens with NTR triggered probe 1 possible in the future. However, the exact molecular mechanism behind this finding remains unknown at this stage. To further evaluate the bacterial imaging efficiency of probe 1 , we determined the timedependent fluorescence responses of probe 1 in live methicillinresistant $S$. aureus (MRSA). As depicted in Fig. S11a (ESI $\dagger$ ), a visible fluorescence signal was observed in MRSA after an incubation time of $10 \mathrm{~min}$ and the Cy 5.5 fluorescence intensity reached to the highest value within approximately $1 \mathrm{~h}$ of incubation, suggesting probe $\mathbf{1}$ is capable of rapid detection of bacterial infections.

This work demonstrates the construction of a novel NTR triggered fluorescence turn-on probe $\mathbf{1}$ with potential applications in medical diagnostics for ESKAPE pathogens. Probe $\mathbf{1}$ displays a highly selective and rapid response of fluorescence enhancement to NTR. In particular, the probe, for the first time, has been successfully applied for real time rapid detection and comparative analysis of NTR activity in ESKAPE pathogens. Due to the substrate specificity of bacterial NTRs, ${ }^{12}$ further studies will focus on the design NTR activatable specific probes for rapidly identifying different pathogens within the ESKAPE collection.

We thank Prof. Ping $\mathrm{Zhu}$, Dr Shu $\mathrm{Xu}$ and their group members (IMM) for their support and valuable discussions. This work was partially supported by the National Natural Science Foundation of China (NSFC) projects (21778077 and 21502236), Sino-German research project (GZ 1271) and the Beijing Nova Program (Z16111000490000).

\section{Conflicts of interest}

There are no conflicts to declare.

\section{Notes and references}

1 (a) M. Urdea, L. A. Penny, S. S. Olmsted, M. Y. Giovanni, P. Kaspar, A. Shepherd, P. Wilson, C. A. Dahl, S. Buchsbaum and G. Moeller, Nature, 2006, 444, 73-79; (b) L. B. Rice, J. Infect. Dis., 2008, 197, 1079-1081; (c) H. W. Boucher, G. H. Talbot, J. S. Bradley, J. E. Edwards, D. Gilbert, L. B. Rice, M. Scheld, B. Spellberg and J. Bartlett, Clin. Infect. Dis., 2009, 48, 1-12.

2 M. van Oosten, M. Hahn, L. M. Crane, R. G. Pleijhuis, K. P. Francis, J. M. van Dijl and G. M. van Dam, FEMS Microbiol. Rev., 2015, 39, 892-916.

3 (a) A. Bunschoten, M. M. Welling, M. F. Termaat, M. Sathekge and F. W. van Leeuwen, Bioconjugate Chem., 2013, 24, 1971-1989; (b) B. Mills, M. Bradley and K. Dhaliwal, Clin. Transl. Imaging., 2016, 4, 163-174; (c) Q. Zhang, Q. Wang, S. Xu, L. Zuo, X. You and H.-Y. Hu, Chem. Commun., 2017, 53, 1366-1369; (d) M. N. Pinto, I. Chakraborty, W. Schultz-Simonton, M. Rojas-Andrade, R. Braslau and P. K. Mascharak, Chem. Commun., 2017, 53, 1459-1462.

4 (a) X. Li, X. Gao, W. Shi and H. Ma, Chem. Rev., 2013, 114, 590-659; (b) J. Wu, B. Kwon, W. Liu, E. V. Anslyn, P. Wang and J. S. Kim, Chem. Rev., 2015, 115, 7893-7943.

5 (a) X. Ning, S. Lee, Z. Wang, D. Kim, B. Stubblefield, E. Gilbert and N. Murthy, Nat. Mater., 2011, 10, 602-607; (b) Y. Kong, H. Yao, H. Ren, S. Subbian, S. L. Cirillo, J. C. Sacchettini, J. Rao and J. D. Cirillo, Proc. Natl. Acad. Sci. U. S. A., 2010, 107, 12239-12244; (c) M. van Oosten, T. Schafer, J. A. Gazendam, K. Ohlsen, E. Tsompanidou, M. C. de Goffau, H. J. Harmsen, L. M. Crane, E. Lim, K. P. Francis, L. Cheung, M. Olive, V. Ntziachristos, J. M. van Dijl and G. M. van Dam, Nat. Commun., 2013, 4, 2584; (d) F. J. Hernandez, L. Huang, M. E. Olson, K. M. Powers, L. I. Hernandez, D. K. Meyerholz, D. R. Thedens, M. A. Behlke, A. R. Horswill and J. O. McNamara II, Nat. Med., 2014, 20, 301-306; (e) G. Feng, Y. Yuan, H. Fang, R. Zhang, B. Xing, G. Zhang, D. Zhang and B. Liu, Chem. Commun., 2015, 51, 12490-12493; $(f)$ K. Ferreira, H.-Y. Hu, V. Fetz, H. Prochnow, R. Rais, P. P. Müller and M. Brönstrup, Angew. Chem., Int. Ed., 2017, 56, 8272-8276.

6 (a) M. Kamiya, D. Asanuma, E. Kuranaga, A. Takeishi, M. Sakabe, M. Miura, T. Nagano and Y. Urano, J. Am. Chem. Soc., 2011, 133, 12960-12963; (b) D. Asanuma, M. Sakabe, M. Kamiya, K. Yamamoto, J. Hiratake, M. Ogawa, N. Kosaka, P. L. Choyke, T. Nagano, H. Kobayashi and Y. Urano, Nat. Commun., 2015, 6, 6463; (c) E. Calatrava-Perez, S. A. Bright, S. Achermann, C. Moylan, M. O. Senge, E. B. Veale, D. C. Williams, T. Gunnlaugsson and E. M. Scanlan, Chem. Commun., 2016, 52, 13086-13089; (d) S. Biswas, B. S. McCullough, E. S. Ma, D. LaJoie, C. W. Russell, D. Garrett Brown, J. L. Round, K. S. Ullman, M. A. Mulvey and A. M. Barrios, Chem. Commun., 2017, 53, 2233-2236; (e) X. He, L. Li, Y. Fang, W. Shi, X. Li and H. Ma, Chem. Sci., 2017, 8, 3479-3483; $(f)$ Q. Zhang, Q. Wang, Y. Sun, L. Zuo, V. Fetz and H.-Y. Hu, Org. Lett., 2017, 19, 4496-4499.

7 (a) P. F. Searle, M. J. Chen, L. Hu, P. R. Race, A. L. Lovering, J. I. Grove, C. Guise, M. Jaberipour, N. D. James and V. Mautner, Clin. Exp. Pharmacol. Physiol., 2004, 31, 811-816; (b) B. D. Palmer, P. van Zijl, W. A. Denny and W. R. Wilson, J. Med. Chem., 1995, 38, 1229-1241; (c) C. Bryant and M. Deluca, J. Biol. Chem., 1991, 266, 4119-4125; (d) D. Bryant, D. McCalla, M. Leeksma and P. Laneuville, Can. J. Microbiol., 1981, 27, 81-86.

8 (a) R. B. Elmes, Chem. Commun., 2016, 52, 8935-8956; (b) X. You, L. Li, X. Li, H. Ma, G. Zhang and D. Zhang, Chem. - Asian J., 2016, 11, 2918-2923; (c) Y. Zhou, K. N. Bobba, X. W. Lv, D. Yang, N. Velusamy, J. F. Zhang and S. Bhuniya, Analyst, 2017, 142, 345-350; (d) D. Li, Y. Xu, N. Zhou, J. Liu, R. Wang, T. Cheng, Y. Tang, W. Zhu, Y. Xu and X. Qian, Dyes Pigm., 2017, 136, 627-632; (e) Z. R. Liu, Y. Tang, A. Xu and W. Lin, Biosens. Bioelectron., 2017, 89, 853-858.

9 (a) Z. Li, X. Gao, W. Shi, X. Li and H. Ma, Chem. Commun., 2013, 49, 5859-5861; (b) R. H. Wong, T. Kwong, K. H. Yau and H. Y. Au-Yeung, Chem. Commun., 2015, 51, 4440-4442.

10 H. Nivinskas, R. L. Koder, Z. Anusevicius, J. Sarlauskas, A.-F. Miller and N. Cenas, Acta Biochim. Pol., 1999, 47, 941-949.

11 R. L. Koder and A.-F. Miller, Biochim. Biophys. Acta, 1998, 1387, 395-405.

12 M. D. Roldan, E. Perez-Reinado, F. Castillo and C. Moreno-Vivian, FEMS Microbiol. Rev., 2008, 32, 474-500. 